\title{
Editorial (ERPP Issue 8.2)
}

\author{
Oon-Seng Tan
}

Received: 5 May 2009 / Accepted: 5 June 2009 / Published online: 23 June 2009

(C) Springer Science+Business Media B.V. 2009

Welcome to the second issue of ERPP for the year 2009. In this issue, we will again explore a wide range of educational issues from the perspectives of policy and practice, and from Asia-Pacific countries/economies of Singapore, Philippines, Malaysia and Hong Kong.

Power's article 'Asia and the Pacific in 2020: Scenarios for Educational Research' brings readers into a futuristic state of mind regarding the future direction of educational research. Power argues that by 2020, the world will have changed and with it the shape and role of education and of educational research. Although the future cannot be predicted with accuracy, his article outlines three possible scenarios, reflecting alternative governmental approaches to the economic, political, social and environmental challenges facing the Asia-Pacific region. For each scenario (labelled loosely: conservative-hierarchical, pragmatic-competitive, utopiancooperative), the goals, structure, policy and practice of education and educational research are outlined, and the implications for the development of educational research and for AsiaPacific Educational Research Association (APERA) are explored.

Tan's article argues that approaches to understanding public policy, such as discourse analysis, are useful for highlighting the differences in understanding the policy, but do not explain how these differences may be explained in relation to each other. Phenomenography and Variation Theory offer an alternative, by examining the variation within, rather than the differences between, experiences of an educational policy. Tan's article traces the development of Phenomenography to Variation Theory, and explains the critical differences between classical Phenomenography and Variation Theory. He argues that Variation Theory is useful for describing educational policy from the perspective of how it is experienced, and that these different ways of experiencing a policy may in turn be understood and utilised in theoretical, analytical and pedagogical ways. The 'Teach Less, learn More' policy in Singapore is used as an example of how differences and contradictions in understanding education policies may cause confusion between intended meaning and actual implementation.

In the article by Vista and Grantham, the authors reported a normative study to investigate the transferability of norms from western-based intelligence tests to Filipino students.

O.-S. Tan $(\varangle)$

National Institute of Education, Nanyang Technological University, Singapore, Singapore

e-mail: oonseng.tan@nie.edu.sg 
More than 2700 Filipino sixth graders were sampled across the country and administered the Naglieri Nonverbal Ability Test (NNAT). Scores were then compared with the US normative sample. The results showed no significant difference in mean scores, and the standardised mean difference was small when scaled scores were used in comparison. However, in situations where the test was used for specific portions of the population such as in the context of gifted education, further analysis revealed that the distribution of scores for the Philippine sample differed significantly from the expected values based on the US norms, particularly in the tail ends of the distribution. The authors opined that in these cases, it might not be valid to transfer the US norms directly for Filipino students without any modification.

The article by Suseela Malakolunthu analyses the 'Vision School' initiative in Malaysia. In the multiracial Malaysian society, a new school redesign model called 'Vision School' has been initiated as yet another measure to foster racial harmony. In this model, the ethnicity-based schools with the medium of instruction in the respective native languages are located within a common compound to share common facilities and organise common school events. Conceptually, the Vision School model is arguably a viable avenue to foster racial unity. However, in reality, the strategies and planned activities are inadequate, simplistic and unproductive. A qualitative investigation of a high-profile Vision School indicated that the goal of racial integration was far from realisation. The approach taken to implement the Vision School was fallacious with inadequacies in the policy formulation and execution. The article provided evidence that the policy cycle, policy instruments and critical action domains needed to be more coherently and sequentially aligned for success.

The article by Lam and Phillipson reports a study of the affective and social outcomes of students in one Hong Kong primary school that streamed students according to achievement level. In response to several major curriculum reforms in Hong Kong since 2000, schools were required to initiate policies that catered for learner diversity, including students with low academic achievement and mild disabilities, and the affective and social outcomes of the learning experience. However, in a Chinese cultural context, parents and students still valued academic achievement very highly. In the study, four hundred and ten students across Primary 3 to 5 responded to four instruments measuring academic self-concept, alienation from school, teacher-students relationship and social integration. The results showed that when studying the regular curriculum, students in the low achievement group reported greater levels of alienation and lowest levels of social integration compared to students with the highest levels of achievement. On the other hand, low achieving students who studied a differentiated curriculum reported affective and social outcomes more consistent with the responses from the high achieving students. The authors opined that there was a mismatch between the aims and practice of the educational policy catering for learner diversity and the expectations of both parents and students.

In every issue of the ERPP, we hope that the papers will generate further discussions and collaborations among educators and researchers so that good educational philosophies and practices may be shared globally. We look forward to your valuable contributions to the ERPP. 